\title{
Journal of Clinical and Translational Hepatology Has Been Indexed in SCIE: A Milestone towards a Greater Academic Goal
}

\author{
Harry Hua-Xiang Xia ${ }^{1}$, George Y. Wu² and Hong Ren*3 \\ ${ }^{1}$ Department of Gastroenterology, First Affiliated Hospital, Guangdong Pharmaceutical University, Guangzhou, Guangdong, \\ China; 2Department of Medicine, Division of Gastroenterology-Hepatology, University of Connecticut Health Center, \\ Farmington, CT, USA; ${ }^{3}$ Institute for Viral Hepatitis, Department of Infectious Diseases, The Second Affiliated Hospital \\ of Chongqing Medical University, Chongqing, China
}

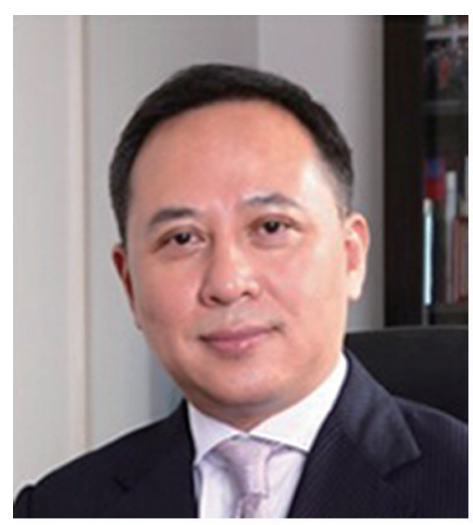

Prof. Hong Ren

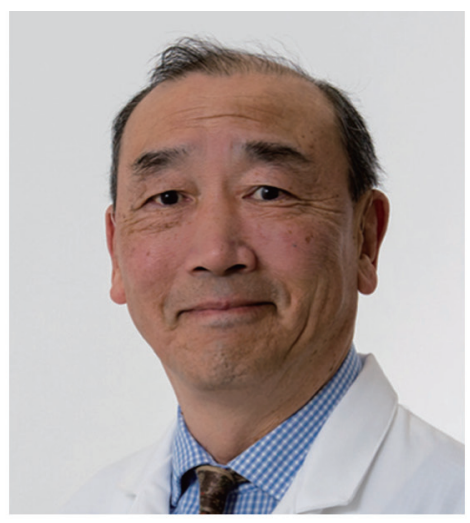

Prof. George Y. Wu

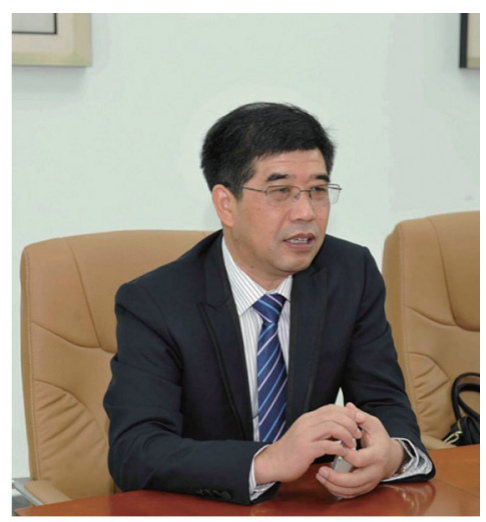

Dr. Harry Hua-Xiang Xia
Citation of this article: $\mathrm{Xia} \mathrm{HH,} \mathrm{Wu} \mathrm{GY,} \mathrm{Ren} \mathrm{H}$. Journal of Clinical and Translational Hepatology has been indexed inSCIE: A milestone towards a greater academic goal. J ClinTransl Hepatol 2020;8(4):357-358. doi: 10.14218/JCTH. 2020.00138.

On November 10, 2020, the Editorial Office received a notification letter from Clarivate Analytics stating that Journal of Clinical and Translational Hepatology (JCTH) had been selected to be included in citation indexes in the Web of Science, and that articles published in JCTH after December 30, 2017 will be listed in some of the most influential and widely used databases in the world, including Current Contents/Clinical Medicine, Science Citation Index Expanded (SCIE), Essential Science Indicators, and Journal Citation Reports Science.

While indexing in the major databases, including PubMed/PubMed Central in 2015, Emerging Science Citation Resources in 2018 and Scopus in early 2020, was testimony to the excellence of JCTH, there was no assurance that the

Abbreviations: JCTH, Journal of Clinical and Translational Hepatology; SCIE, Science Citation Index Expanded.

Received: 02 December 2020; Revised: 12 December 2020; Accepted: 13 December 2020

*Correspondence to: Hong Ren, The Second Affiliated Hospital of Chongqing Medical University, Chongqing 400010, China. E-mail: renhong0531@vip.sina. com
Journal would be accepted by the most exclusive of indices. We - Prof. Hong Ren, the General Editor-in-Chief; Prof. George Y. Wu, Comprehensive Editor-in-Chief; and Dr. Harry Hua-Xiang Xia, Co-Editor-in-Chief - have attempted to provide strategic vision, effective leadership, and stringent ethical standards for the Journal. But, all of this would have been of little consequence had it not been for the tremendous contributions of the associate editors, editorial board members, reviewers, authors, and staff of the editorial office. It is primarily because of their collective efforts that JCTH has achieved worldwide recognition in the competitive environment of academic publishing. Therefore, we, on behalf of the Journal, wish to take this opportunity to thank all of those individuals who have worked so hard and done so well to date.

On this momentous occasion, it is fitting to review the history of JCTH and the journey that led to its current status. The initiation and preparation for the creation of the Journal began in the Spring of 2010, when Dr. Xia was told by Dr. Qingfeng Sun from The Third Affiliated Hospital to Wenzhou Medical University that Prof. Ren, the Editor-in-Chief of a prestigious Chinese journal named Chinese Journal of Hepatology, intended to launch an English language journal in hepatology for The Second Affiliated Hospital of Chongqing Medical University, China. He approached Prof. Dazhi Zhang, Director of the Editorial Office of Chinese Journal of Hepatology, and the two had a very productive conversation. After several rounds of teleconferences and personal meetings in 
Xiamen, Chongqing, and Guangzhou, a general consensus was achieved that the project was worthwhile and feasible.

Xia \& He Publishing Limited was engaged to undertake the task. Xia \& He Publishing Limited had been originally registered since July 29, 2011 in Hong Kong, and was later established as Xia \& He Publishing Inc. on January 8, 2015 in the USA under the very capable management of Dr. Hua He. The contract for publishing JCTH was signed by Prof. Ren and Dr. Xia on November 29 and December 8, 2011, respectively. In the meantime, Dr. Xia cordially invited Prof. Wu to be the Comprehensive Editor-in-Chief, owing to his remarkable academic record and international reputation. Dr. Xia and Prof. Wu, along with his wife, Prof. Catherine Wu, first met on November 27, 2010. In that and subsequent meetings and relaxed conversations - of course, over lunch at Chinese restaurants - numerous common views and perspectives were shared on the proposed journal.

After more than 2 years of preparation, JCTH was officially launched in September 2013, with an initial issue that featured an editorial entitled "Found in Translation" by Prof. Wu. ${ }^{1}$ Since then, JCTH has published quarterly, yielding 29 issues with 361 peer-reviewed articles as of November 10, 2020. Of these articles, $92.0 \%$ are original and review articles, and $54.6 \%$ have been financially supported from various research funding sources, with The National Institutes of Health and National Natural Science Foundation of China listed as sponsors of the research in $24.9 \%$ of the articles. From the outset, JCTH sought to be diverse, international, and inclusive in both its articles and review panels; for the latter, the success of this approach is reflected by the composition of the Editorial Board, which now consists of 143 experts from 23 countries and regions, with $37.1 \%$ from China and $32.2 \%$ from the USA, followed by Egypt, India, Italy, etc. The corresponding authors of the articles published in JCTH to date are from 32 countries and regions, with $35.5 \%$ of them from the USA and $23.0 \%$ from China, followed by India, Egypt, Italy, etc. The reviewers are from 40 countries and regions, with $24.8 \%$ of them from the USA and $19.2 \%$ from China, followed by Japan, India, Italy, etc.

According to the Web of Science, as of November 10 , 2020, the most cited JCTH article has been referenced 205 times, ${ }^{2}$ and one of the articles on COVID-19 published in the early 2020 has already been cited 56 times. ${ }^{3}$ The readership interest in and academic influence of JCTH have also been reflected by estimated unofficial impact factors for 2017, 2018 and 2019 of $3.615,3.489$ and 4.546, respectively, with a self-citation rate of only $1.4 \%$. In June 2021 , JCTH will receive its first official impact factor, which is expected to be around 3.5 .

While indexing in SCIE is a major achievement and a remarkable milestone for JCTH, it is obviously not the final goal. As stated in our inaugural issue, "the objective of the Journal of Clinical and Translational Hepatology is to identify and publish articles that represent translations of fundamental research to contributions of direct practical value". ${ }^{1}$ In all that JCTH does, this is and will remain the fundamental and paramount mission. That objective is also symbolized in our logo, in which translational research promotes the proper placement of pieces of a puzzle to form an ever more accurate picture of the liver. However, in the pursuit of this objective, we are planning to further increase the international influence of JCTH by inviting more highprofile experts to the editorial board and further increasing the standards for manuscripts to be published in the Journal. Within the next 10 years, we will strive for the Journal to become listed among the top $25 \%$ of journals in gastroenterology and hepatology, according to the Web of Science Journal Citation Reports.

In closing, we wish to share reflections that encapsulate the vision for the future of JCTH as composed by Dr. Xia in Chinese, with English translation in parentheses:

同谋肝胆志,
共表中华情.
十年磨一剑,
携手启新程.

(With a graceful ambition and careful preparation, We determined to launch an internationally influential hepatology journal in China.

With such a major milestone met after 10 years of persistence and endeavor,

We start a new journey toward a greater goal together.)

\section{Funding}

None to declare.

\section{Conflict of interest}

The authors have no conflict of interests related to this publication.

\section{References}

[1] Wu GY. Found in translation. J Clin Transl Hepatol 2013;1:1. doi: 10.14218/ JCTH.2013.000XX

[2] Yoon E, Babar A, Choudhary M, Kutner M, Pyrsopoulos N. Acetaminopheninduced hepatotoxicity: a comprehensive update. J Clin Transl Hepatol 2016:4:131-142. doi: 10.14218/]CTH.2015.00052.

[3] Feng G, Zheng KI, Yan QQ, Rios RS, Targher G, Byrne CD, et al. COVID-19 and liver dysfunction: Current insights and emergent therapeutic strategies. J Clin Transl Hepatol 2020;8:18-24. doi: 10.14218/JCTH.2020.00018. 